\title{
Isıl İşlem Uygulamalarında Kullanılan Bir Karışım Tankının Bulanık Mantık Esaslı Denetimi
}

\author{
Erdal KILIÇ ${ }^{*}$, Hasan Rıza ÖZÇALIK ${ }^{2}$, Şaban YILMAZ ${ }^{3}$, Ahmet GANí2 \\ ${ }^{1}$ Kahramanmaraş Sütçü İmam Üniversitesi, Afşin Meslek Yüksekokulu, Kahramanmaraş, Türkiye \\ ${ }^{2}$ Kahramanmaraș Sütçü İmam Üniversitesi, Elektrik-Elektronik Mühendisliği, Kahramanmaraş, Türkiye \\ ${ }^{3}$ Kahramanmaraş Sütçü İmam Üniversitesi, Kahramanmaraş Meslek Yüksekokulu, Kahramanmaraş, Türkiye
}

\begin{abstract}
ÖZET: Karışım tanklarının kontrolü, gıda sanayi, tarımsal ilaçlama, tekstil, atık su arıtma, süt üretimi, nükleer enerji üretimi, petrokimya endüstrisi, kimyasal süreçler ve ilaç sanayi gibi endüstriyel uygulamalar için çok önemlidir. Bu çalışmada çok girişli çok çıkışlı ve doğrusal olmayan bir sistem olan sıvı karışım tankının kontrolü, MATLAB/Simulink benzetim programı ile yapılmıştır. Bu karışım tankına iki pompa vasıtasıyla sıcak ve soğuk su akışı sağlanmaktadır. Suyun akış miktarı valfler ile kontrol edilerek, tankta istenilen su sıcaklığı ve seviyesi elde edilmektedir. Kontrol sistemi, karışım tankı içindeki suyun seviye ve sıcaklığını istenilen değerlerde tutmak amacıyla iki bağımsız bulanık mantık denetleyiciden oluşmaktadır.
\end{abstract}

Anahtar Kelimeler: Bulanık Mantık Denetim, Sıvı Seviye Kontrolü, Karışım Tankı.

\section{Fuzzy Logic Based Control of the Mixing Tank Used in Heat Treating Applications}

\begin{abstract}
Controlling mixing tanks is of utmost importance for industrial applications such as food processing, agricultural pesticides, textile, waste water treatment, dairy production, nuclear power generation, petrochemical industries, chemical processing and pharmaceutical manufacturing. In this study, fluid mixing tank, which is a nonlinear multi input multi output system, is simulated by MATLAB/Simulink. Hot and cold water flow is provided to the mixing tank through two water pumps. Desired water temperature and level in the tank is obtained thanks to the water flow valves. The control system consists of two independent fuzzy logic controllers in order to keep the desired level and temperature of the water in the mixing tank.
\end{abstract}

Keywords: Fuzzy Logic Control, Liquid Level Control, Mixed Tank.

\section{GIRISŞ}

Karışım tanklarının kontrolü, gıda sanayi, tarımsal ilaçlama, tekstil, atık su arıtma, süt üretimi, nükleer enerji üretimi, kimyasal işleme, ilaç sanayi gibi endüstriyel uygulamalar için çok önemlidir [1-6]. İki veya daha fazla sıvının karışımından oluşan endüstriyel sıvı karıştırma süreçleri kontrol ve otomasyon sistemleri ile denetlenmektedir [7]. Karışım tankı çok girişli çok çıkışlı ve doğrusal olmayan dinamik bir sistemdir $[6,8]$.

Bulanık mantık uygulamaları 1sı, elektrik akımı, sıvı gaz akım denetimi, kimyasal ve fiziksel süreç denetimlerinde kullanılmaktadır. Bulanık mantık yaklaşımı matematiksel modele ihtiyaç duymadığından, matematiksel modeli iyi tanımlanamamış, zamanla değişen ve doğrusal olmayan sistemler en başarılı uygulama alanlarıdır [9].

Bu çalışmada iki girişli ve iki çıkışlı bir karışım tankı ve kontrol sistemi MATLAB/Simulink benzetim programı ile modellenmiştir. Karıșım tankına iki pompa vasitasıyla sıcak ve soğuk su akışı sağlanmaktadır. Suyun akış miktarı valfler ile kontrol edilerek, tankta istenilen su sıcaklığg ve su seviyesi elde edilmektedir. Sistemi kontrol etmek amacıyla iki girişli iki çıkışlı bulanık mantık esaslı bir kontrol yöntemi geliştirilmiştir. Sistemin çalışması simülasyon ortamında test edilmiştir.

\section{SISTEMIN YAPISI}

$\mathrm{Bu}$ çalışmada dikdörtgen prizma şeklinde bir su tankı kullanılmıştır. Tanka $0,025 \mathrm{~m}^{3} / \mathrm{s}$ debiyle çalışan pompalar vasıtasıyla sıcak su ve soğuk su verilmektedir. Tanka giren sıcak ve soğuk suyun akış miktarı, istenilen su seviyesine ve su sicaklığına göre denetleyiciler tarafindan kontrol valfleri ayarlanarak yapılmaktadır. Tanktan su çıkışı için kullanılan boşaltma vanasının ayarı ise kullanıcı tarafindan manuel olarak yapılmaktadır. Karışım tank sisteminin genel yapısı Şekil-1'de gösterilmektedir.

*Sorumlu Yazar: Erdal KILIÇ, ekilic@ksu.edu.tr 


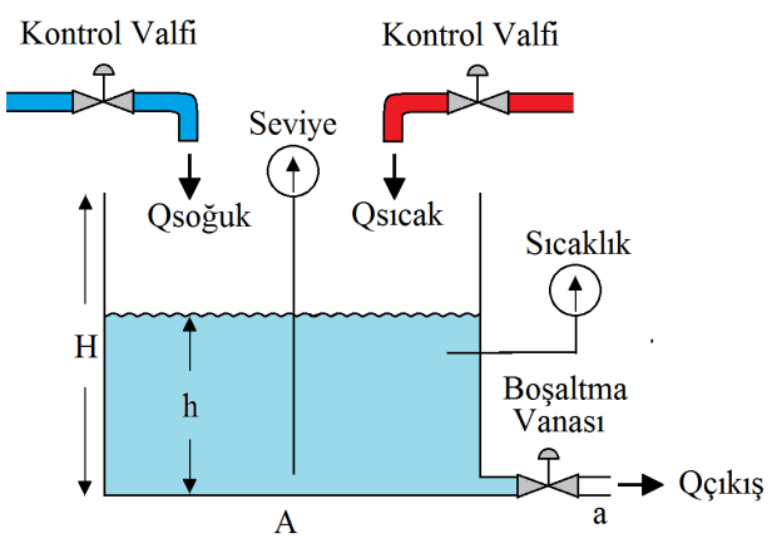

Şekil-1. Sistemin genel yapısı

Tanka giren sicak suyun sıcaklığ $1\left(T_{I}\right)$ ve soğuk suyun sicaklığı $\left(T_{2}\right)$ değerleri sabit kabul edilmektedir. Karışım tankına giren sıcak su akışı $Q_{\text {sicak }}=Q_{\text {maks }} * C_{\text {sicak }}$ ile soğuk su akışı $Q_{\text {soğuk }}=Q_{m a k s} * C_{\text {soğuk }}$ şeklinde tanımlanmıştır. Burada $Q_{\text {maks }}$ pompa kapasitesini, $C_{\text {sicak }}$ ve $C_{\text {soğuk }}$ kontrol valflerinin (0-1) aralığındaki açıklık oranını göstermektedir. Tanka giren toplam su akış miktarı $Q_{\text {giris }}=Q_{1}+Q_{2}$, karışım suyunun sıcaklığ $T$ ve

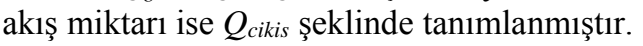

Tanktaki suyun seviyesini ve sıcaklığını kontrol etmek amaciyla sistem dinamiklerini ifade eden diferansiyel denklemler, denklem 1, 2 ve 3 'te verilmiştir [1,10-14].

$Q_{\text {cikis }}=a \sqrt{2 g h}$

$\frac{d h}{d t}=\frac{1}{A}\left(Q_{\text {sicak }}+Q_{\text {soguk }}-Q_{\text {cikis }}\right)$

$\frac{d T}{d t}=\frac{1}{A h}\left[Q_{\text {sicak }}\left(T_{1}-T\right)+Q_{\text {soguk }}\left(T_{2}-T\right)\right]$

Burada $h$ tanktaki suyun yüksekliğini, $A$ tankın taban alanını göstermektedir. Bu çalışmada kullanılan su tankının yapısı ile ilgili değerler Tablo-1'de verilmiştir.

Tablo-1. Su tankının özellikleri

\begin{tabular}{lcl} 
Açıklama & Sembol & Değer \\
\hline Taban alanı & $A$ & $1 \mathrm{~m}^{2}$ \\
\hline Çıkış ağzı kesiti & $a$ & $0,025 \mathrm{~m}^{2}$ \\
\hline Yükseklik & $H$ & $2.5 \mathrm{~m}$ \\
\hline Yer çekim ivmesi & $g$ & $9,82 \mathrm{~m} / \mathrm{s}^{2}$ \\
\hline Başlangıç seviyesi & $h_{0}$ & $0.1 \mathrm{~m}$ \\
\hline Pompa kapasitesi & $Q_{\text {maks }}$ & $0,025 \mathrm{~m}^{3} / \mathrm{s}$ \\
\hline Sicak su sıcaklı̆̆1 & $T_{1}$ & $80{ }^{\circ} \mathrm{C}$ \\
\hline Soğuk su sıcaklı̆̆1 & $T_{2}$ & $10^{\circ} \mathrm{C}$ \\
\hline Başlangıç sıcaklığ1 & $T_{0}$ & $10^{\circ} \mathrm{C}$ \\
\hline
\end{tabular}

\section{BULANIK MANTIK DENETLEYICİ}

Bulanık mantık yaklaşımı, makinelere insanların özel verilerini işleyebilme ve onların deneyimlerinden ve önsezilerinden yararlanarak çalışabilme yeteneği verir. $\mathrm{Bu}$ yeteneği kazandırırken sayısal ifadeler yerine sembolik ifadeler kullanır. Bulanık mantık denetleyici (BMD)'nin temeli sözlü ifadeler ve bunlar arasındaki mantıksal ilişkiler üzerine kurulmuştur. Bulanık mantık, klasik mantığın aksine iki seviyeli değil, çok seviyeli işlemleri kullanmaktadır. BMD uygulanırken sistemin matematiksel modellenmesi şart değildir [9].

BMD, zamanla değişen, doğrusal olmayan ve özellikle matematiksel modeli tam olarak bilinmeyen sistemlerin denetlenmesinde son yıllarda klasik denetim yöntemlerine pratik bir alternatif olarak ortaya çıkmıştır [15].

BMD, genel yapısıyla bulandırma, çıkarım, durulama ve bilgi tabanı olmak üzere dört temel bileşenden oluşmuştur. Genel bir BMD blok diyagramı Şekil-2’de verilmiştir.

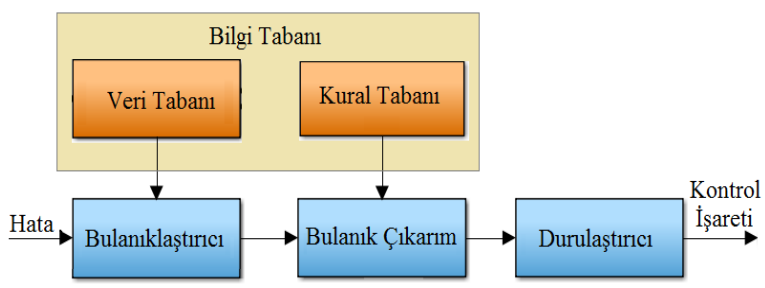

Şekil-2. Bulanık mantık denetleyici yapısı

Bulandırma birimi, sistemden alınan giriş bilgilerini dilsel niteleyiciler olan sembolik değerlere (đönüştürme işlemidir. Üyelik işlevinden faydalanılarak giriş bilgilerinin ait olduğu bulanık kümeleri ve üyelik derecesi tespit edip, girilen sayısal değere küçük, en küçük gibi dilsel değişken değerler atanır.

Bulanık çıkarım birimi, bulandırma biriminden gelen bulanık değerleri, kural tabanındaki kurallar üzerinde uygulayarak bulanık sonuçlar üretilmektedir. Girişler ve çıkışlar arasındaki bağlantılar, kural tabanındaki kurallar kullanılarak sağlanır. $\mathrm{Bu}$ birimde elde edilen değer kural tablosundan dilsel ifadeye çevrilir ve durulama birimine gönderilir. Bulanık çıkarım yöntemleri içerisinde en yaygın kullanılan ve bu çalışmada da kullanılan yöntem Mamdani yöntemidir.

Durulama birimi, karar verme biriminden gelen bulanık bir bilgiden bulanık olmayan ve uygulamada kullanılacak gerçek değerin elde edilmesini sağlar. Durulama, bulanık bilgilerin kesin sonuçlara dönüştürülmesi işlemidir. 
Durulama işleminde değişik yöntemler esas alınmaktadır. Bu yöntemlerden ağırlık merkezi yöntemi en yaygın kullanılan durulama yöntemidir.

$$
y=\frac{\sum_{i=1}^{n} y_{i} \cdot \mu_{A}\left(y_{i}\right)}{\sum_{i=1}^{n} \mu_{A}\left(y_{i}\right)}
$$

Bilgi tabant, denetlenecek sistemle ilgili bilgilerin toplandığı bir veri tablosundan ibarettir. Girişler ve çıkışlar arasındaki bağlantılar, kural tabanındaki kurallar kullanılarak sağlanır. Bir sistem için kural tabanı geliştirilirken, sistem çıkışını etkileyebilecek giriş değerleri tespit edilmelidir. Bulanık kontrol kuralları genellikle uzman bilgisinden türetilir [9,16-18].

\section{SISTEMIN SIMULINK YAPISI}

$\mathrm{Bu}$ çalışmada MATLAB/Simulink benzetim programı ile bütün sistem elemanlarının modelleri oluşturularak karışım tankının modeli elde edilmişstir. Tanka giren suyun akış miktarını kontrol etmek için kullanılan akış kontrol valfinin simulink modeli Şekil3 'te gösterilmiştir [19-20].

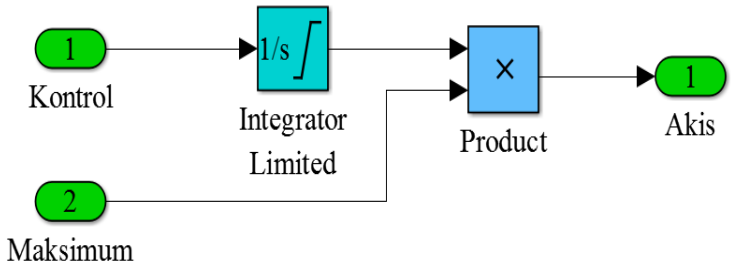

Şekil-3. Valfin simulink modeli

Karışım tankının simulink modeli Şekil-4’teki gibidir.

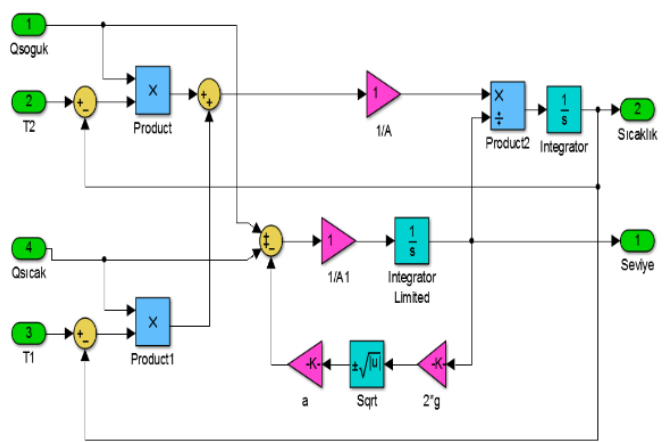

Şekil-4. Su tankının simulink modeli.

Karışım tankının sıcaklık ve seviye kontrolünün oluşturulduğu sistemin simulink modeli Şekil-5'te gösterilmiştir.

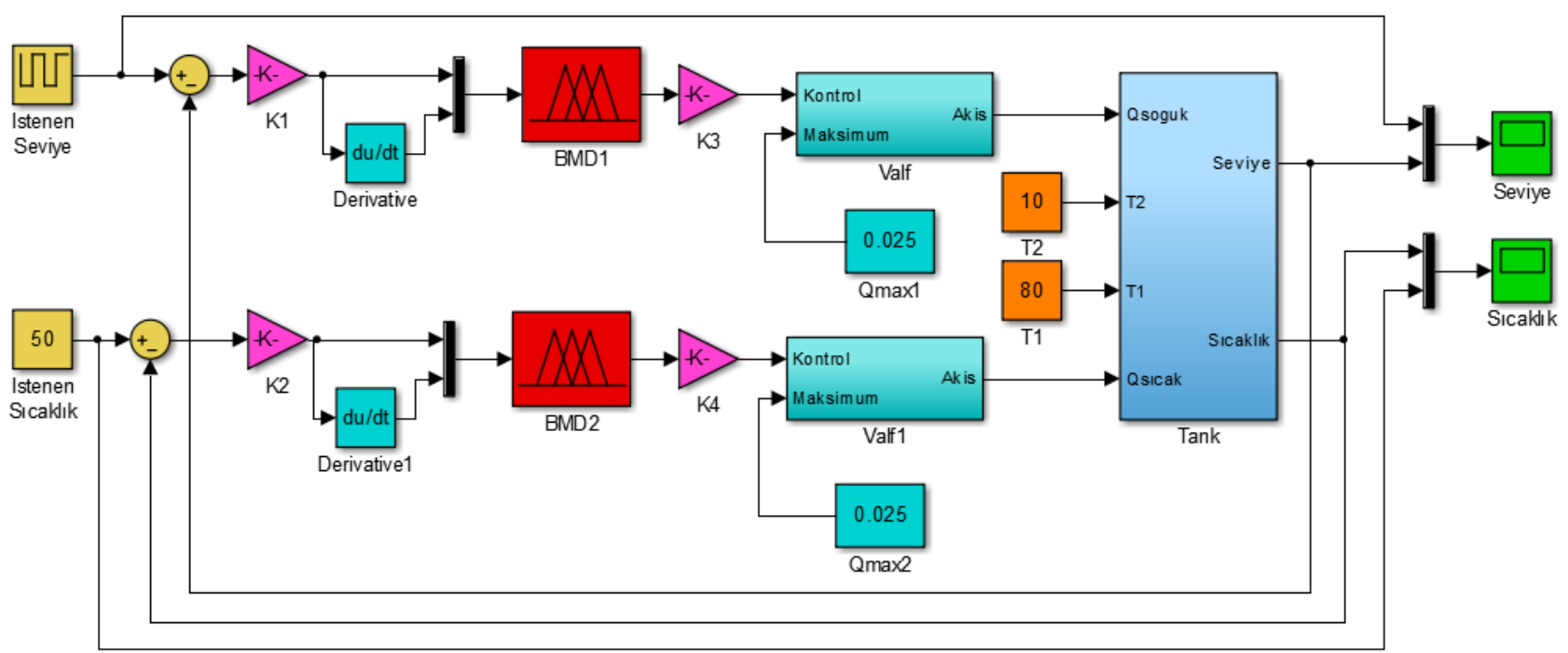

Şekil-5. Sistemin simulink modeli

\section{BMD TASARIMI}

BMD’nin tasarım aşamasında, giriş ve çıkış değişkenlerinin, bulanık kümelerin tanımlanmasının, kuralların, bulanık çıkarımın ve durulama işleminin belirlenmesi gerekmektedir.

Bulandırma işleminde giriş ve çıkış değişkenleri sembolik ifadelere dönüştürülmektedir. Denetleyicinin dilsel değişkenleri NB (Negatif Büyük), NK (Negatif Küçük), SS (Sıfır), PK (Pozitif Küçük), PB (Pozitif Büyük) şeklinde kullanılmıştır. BMD'nin yapısı Şekil6'da gösterilmiştir. 


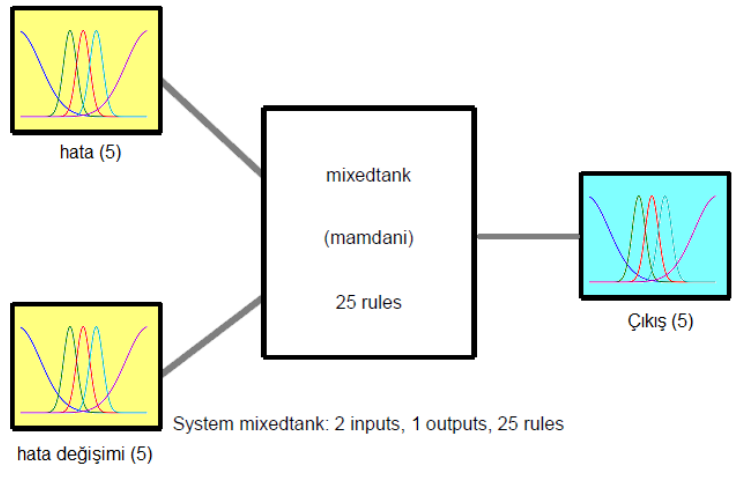

Şekil.6. BMD giriş ve çıkış değişkenleri

Her BMD için iki tane giriş seçilmiştir. Bu girișler seviye denetleyici için seviye hatası $\left(\mathrm{e}_{1}\right)$ ve seviye hata değişimi $\left(\Delta \mathrm{e}_{1}\right)$, sıcaklık denetleyici için sıcaklık hatası $\left(\mathrm{e}_{2}\right)$ ve sicaklık hata değişimi $\left(\Delta \mathrm{e}_{2}\right)$ parametreleridir. $k$ iterasyon sayısını göstermek üzere hataların ifadesi denklem 5 ve 6 'da verilmiştir.

$e_{1}(k)=h_{r e f}(k)-h(k)$

$e_{2}(k)=t_{r e f}(k)-t(k-1)$

Bu çalıșmada girișler ve çıkışlar için Şekil-7'de gösterilen gaussian tipi üyelik fonksiyonu kullanılmıştır.

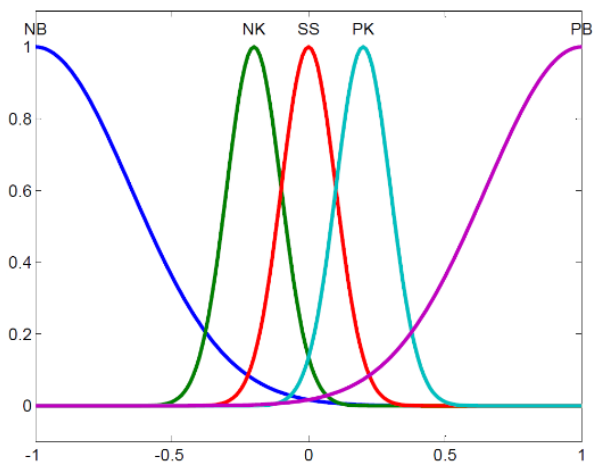

Şekil-7. Üyelik fonksiyonları

Bulanık çıkarım biriminde girişlerin çıkış ile ilişkisi belirlenen kurallarla sağlanır. Bulanık çıkarım için birçok farklı yapı kullanılmaktadır. Bu çalışmada min-max çıkarım yapısı kullanılmıştır vee her denetleyici için 25 adet kural yazılmıştır. Kural tablosu Tablo-2'de verilmiştir.

Tablo-2. Bulanık kural tablosu.

\begin{tabular}{lllllll}
\hline \multirow{2}{*}{$u$} & \multirow{2}{l}{$u$} & \multicolumn{5}{c}{$\Delta e$} \\
\cline { 2 - 7 } & NB & NK & SS & PK & PB \\
\hline \multirow{3}{*}{$e$} & NB & NB & NB & NK & SS \\
\cline { 2 - 7 } & NK & NB & NB & NK & SS & PK \\
\cline { 2 - 7 } & SS & NB & NK & SS & PK & PB \\
\cline { 2 - 7 } & PK & NK & SS & PK & PB & PB \\
\cline { 2 - 7 } & PB & SS & PK & PB & PB & PB \\
\hline
\end{tabular}

Durulama biriminde, her kural için hata ve hata değişiminin üyelik ağırlık değerleri bulunarak, bu iki değerin en az üyelik ağırlığ 1 ve buna göre çıkışların üyelik değerleri tespit edilmektedir. Durulama biriminin çıkışındaki sayısal değer sisteme uygulanan gerçek değerdir.

\section{SIMMÜLASYON SONUÇLARI}

Simülasyon çalışmasında sisteme ilk olarak sıcaklık sabit referansta iken değişken seviye referansı verilmiştir. Bu durumda elde edilen seviye grafiği Şekil8'de gösterilmiștir.

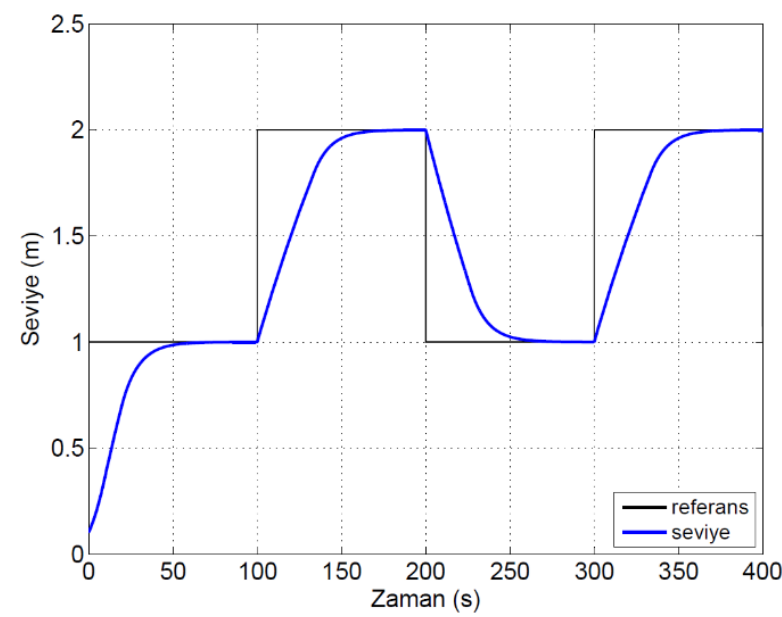

Şekil-8. Değișken referanslı seviye grafiği

Seviye denetleyicisi tanktaki su seviyesini referans değerlere oldukça başarılı bir şekilde yaklaştırmış̧ır. Aynı zamanda sıcaklık denetleyicisi de suyun sıcaklık değerini istenilen değere ulaştırmıştır. Seviye referans değerlerinin değişimi sistemde bozucu etki oluşturmaktadır. Bu değişim noktalarında sıcaklık değerlerinde \%4'lük bir hata meydana gelmiştir. $\mathrm{Bu}$ hatalar sıcaklık denetleyici tarafindan başarı bir şekilde düzeltilmiştir. Sıcaklık grafiği Şekil-9'da verilmiştir.

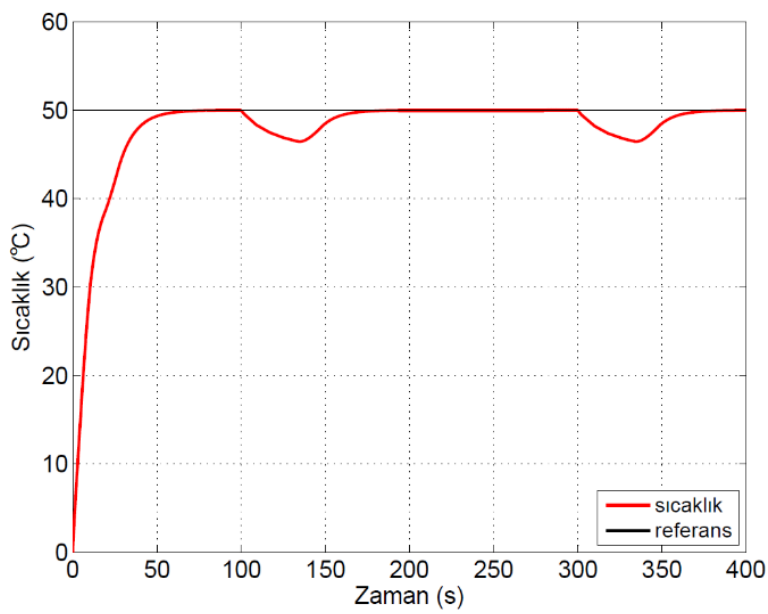

Şekil-9. Sabit referanslı sıcaklık grafiği 
Simülasyon çalışmasının ikinci kısmında ise sistemde, seviye referans değeri sabit iken değişken sıcaklık referansı verilmiştir. Seviye grafiği Şekil-10'da gösterilmiştir.

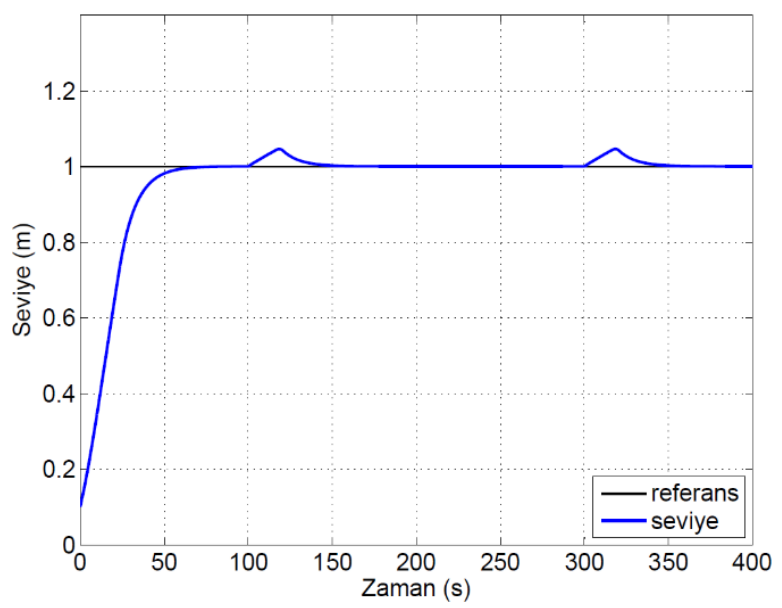

Şekil-10. Sabit referanslı seviye grafiğgi

Sistemdeki sicaklık denetleyicisi, tanktaki suyun sıcaklığını istenilen değerlere yaklaştırmıştır. Seviye denetleyicisi de suyun seviyesini istenilen değere ulaştırmıştır. Seviye değişiklik çalışmasında olduğu gibi sıcaklık referans değerlerinin değişimi de sistemde bozucu etki oluşturmuştur. $\mathrm{Bu}$ değişim noktalarında seviye değerlerinde yaklaşık \%5'lik bir hata meydana gelmiştir. Bu hatalar seviye denetleyici tarafindan kısa sürede düzeltilmiştir. Bu çalışma durumunda elde edilen sıcaklık grafiği Şekil-11'de verilmiştir.

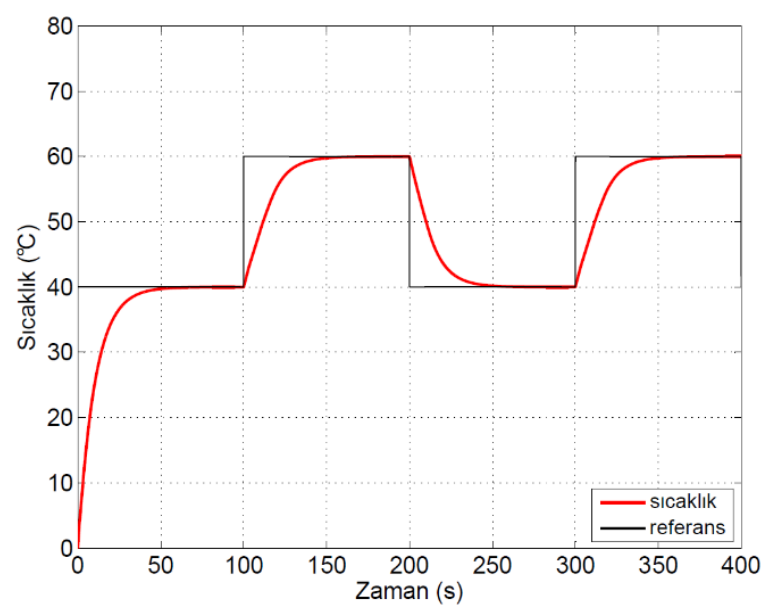

Şekil-11. Değişken referanslı sıcaklık grafiği

\section{SONUÇ}

Bu çalışmada iki girişli iki çıkışlı bir sıvı karışım tankının seviye ve sicaklık denetim sistemi MATLAB/Simulink ile modellenmiştir. Sistemin seviye ve sıcaklık değişkenlerinin kontrolünde iki bağımsız BMD yaklaşımı ile başarılı sonuçlar elde edilmiştir.
Hem seviye kontrolünde hem de sicaklık kontrolünde aşım olmadığ 1 gözlemlenmiştir. Her iki çıkış değişkeni sonuçları incelendiğinde yükselme zamanı 45 $\mathrm{s}$, yerleşme zamanı $50 \mathrm{~s}$ ve kararlı hal hatasının çok küçük olduğu görülmüştür. Ayrıca BMD sistemde oluşan bozucu etkileri kısa bir sürede düzeltmiştir.

$\mathrm{Bu}$ çalışma ile çok girişli çok çıkışlı doğrusal olmayan dinamik yapıdaki bir sistemin kontrolünde BMD'nin iyi bir denetim performansına sahip olduğu gözlemlenmiştir.

\section{KAYNAKLAR}

[1]. Güneş, M., Arslan, S., Bay, A.E., “ Çok Fonksiyonlu Bir Elektronik Pülverizatörde İlaçlama İşleminin Optimal ve Bulanık Kontrolü”, KSU Mühendislik Bilimleri Dergisi, 16(2), 2013.

[2]. Pradeepkannan, D., Sathiyamoorthy, S., "Design and Modeling of State Feedback with Integral Controller for a Non-linear Spherical tank Process", International Journal of Emerging Technology and Advanced Engineering, ISSN 2250-2459, Volume 2, Issue 11, November 2012.

[3]. Tiwari, S.K., Kaur, G., "Analysis of Fuzzy PID and Immune PID Controller for Three Tank Liquid Level Control", International Journal of Soft Computing and Engineering (IJSCE) ISSN: 22312307, Volume-1, Issue-4, September 2011.

[4]. Hasan, S., Khan, S.K., Alam, S., "Design and Implemetation of a Neural Control System and Performance Characterization with PID Controller for Water Level Control", International Journal of Artificial Intelligence \& Applications (IJAIA), Vol.2, No.2, April 2011.

[5]. Aslam, F., Haider, M.Z., "An Implementation and Comparative Analysis of PID Controller and their Auto Tuning Method for Three Tank Liquid Level Control", International Journal of Computer Applications (0975 - 8887) Volume 21- No.8, May 2011.

[6]. Lanas, A.I, Mota, G.L.A., Tanscheit, R., Vellasco, M.M., Barreto, J.M., " Fuzzy Control of a Multivariable Nonlinear Process”, In Proceedings of eight International Fuzzy Systems Association World Congress, Vol.2 (8), pp. 660-664, 1999.

[7]. Şahin, S., "Endüstriyel Otomasyon Eğitimi İçin Lookout Yazılım Tabanlı Sıvı Karışım Süreci Tasarımı", SDU Teknik Bilimler Dergisi, Cilt.2, Say1.1, SS.42-45, 2012.

[8]. Damarla, S.K., Kundu, M., "Design of Multivariable Neural Controllers using a Classical Approach", International Journal of Chemical 
Engineering and Applications, Vol. 1, No. 2, August 2010.

[9]. Elmas, Ç., "Yapay Zeka Uygulamaları”, Seçkin Yayıncılık, 2.Baskı, Ankara, 2011.

[10]. Özçalık, H.R., Kılıç, E., Yılmaz, Ş., Gani, A., "Bulanık Mantık Esaslı Sıvı Seviye Denetiminde Farklı Üyelik Fonksiyonlarının Denetim Performansina Etkisinin İncelenmesi”, Otomatik Kontrol Ulusal Toplantıs1, TOK2013, 26-28 Eylül 2013, Malatya, S.243-247.

[11]. Shahgholian, G., Movahedi, A., "Modeling and Controller Design Using ANFIS Method for NonLinear Liquid Level System", International Journal of Information and Electronics Engineering, Vol. 1, No. 3, November 2011.

[12]. http://wikis.controltheorypro.com/images/MIMOarticle.doc Access Time: 15.09.2014 14.20 PM.

[13]. Engin, S.N., Kuvulmaz, J., Ömürlü, V.E., "Fuzzy Control of an ANFIS Model Representing A Nonlinear Liquid-Level System" Neural Computer \& Application (2004) 13:202-210.

[14]. Kılıç, E., Özbalcı, Ü., Özçalık, H.R., "Lineer Olmayan Dinamik Sistemlerin Yapay Sinir Ağları ile Modellenmesinde MLP ve RBF Yapılarının Karşılaştırılması", Eleco 2012 Elektrik-Elektronik ve Bilgisayar Mühendisliği Sempozyumu Bildiriler Kitabı, S.694-698, 29 Kasım - 01 Aralık 2012, Bursa.

[15]. Passino,K., and Yurkovich S., Fuzzy Control, Addison-Wesley Publishing Company, 1998.

[16]. Özkop, E., Altaş, İ.H., "Bulanık Mantık Denetleyici ile Aktif Otomobil Süspansiyon Denetimi” XII. EEBB Mühendisliği Ulusal Kongresi Ve Fuarı, Eskişehir Osmangazi Üniversitesi, Eskişehir. Kasım 14-18, 2007.

[17]. Şekkeli, M., Yıldız, C., Özçalık H.R., "Bulanık Mantık ve PI Denetimli DC-DC Konvertör Modellenmesi ve Dinamik Performans Karşılaştırılması", 4. otomasyon sempozyumu , Samsun ,Mayıs 2007.

[18]. Özek, A., Sinecen, M., "Klima Sistem Kontrolünün Bulanık Mantık ile Modellenmesi”, Pamukkale Üniversitesi Mühendislik Fakültesi Mühendislik Bilimleri Dergisi, Cilt:10,Say1:3, Sayfa: 353-358, Y1l:2004.

[19]. Dharamniwas, Ahmad, A., Redhu, V., Gupta, U., "Liquid Level Control by Using Fuzzy Logic Controller", International Journal of Advances in Engineering \& Technology, July 2012, ISSN: 2231-1963.

[20]. Jiang, W., "The Application of the Fuzzy Theory in the Design of Intelligent Building Control of
Water Tank", Journal of Software, Vol. 6, No. 6, June 2011. 